\title{
Local anesthesia for pain control during transrectal ultrasound-guided prostate biopsy: a systematic review and meta-analysis
}

This article was published in the following Dove Press journal: Journal of Pain Research

II October 2016

Number of times this article has been viewed

Pu Yan*

Xiao-yan Wang*

Wei Huang

Yong Zhang

Beijing Tian Tan Hospital, Capital Medical University, Neurology Research Division, China National Clinical Research Center for Neurological Disease, Beijing, People's Republic of China

*These authors contributed equally to this work.
Correspondence: Yong Zhang

Department of Urology, Beijing Tian

Tan Hospital, Capital Medical University, No 6 Tiantan Xi Li, Dong Cheng District, Beijing 100050, People's Republic

of China

Tel +86 I0 67098393

Fax +861067096611

Email186I07II834@I63.com
Background: A meta-analysis was performed to evaluate the efficacy and safety of intrarectal local anesthestic (IRLA), periprostatic nerve block (PPNB), and the combined modalities in alleviating the pain during transrectal ultrasound (TRUS)-guided prostate biopsy.

Materials and methods: A literature review was performed to identify all published randomized controlled trials (RCTs) about IRLA vs no anesthesia or placebo gel; PPNB vs no injection, periprostatic placebo injection, or IRLA; combined PPNB and IRLA vs PPNB alone; and combined PPNB and intraprostatic nerve block (IPNB) vs PPNB alone before TRUS-guided biopsy. Sources included MEDILINE, EMBASE, and Cochrane Library from 1980 to 2016. The main outcomes were biopsy pain score, probe manipulation pain score, and anesthetic infiltration pain score assessed by the visual pain scale.

Results: A total of 26 articles involving 36 RCTs were used in this analysis: Although IRLA can lead to pain reduction, the result was not statistically significant when compared with no anesthesia or placebo gel (weighted mean difference [WMD]: $-0.22,95 \%$ CI: -0.45 to 0 , $P=0.06$ ). PPNB can lead to significantly lower biopsy pain scores when compared with no analgesia (WMD: $-1.32,95 \% \mathrm{CI}:-1.68$ to $-0.95, P<0.00001$ ), placebo injection (WMD: $-2.62,95 \%$ CI: -3.16 to $-2.07, P<0.00001$ ), or IRLA (WMD: $-1.31,95 \%$ CI: -1.40 to -1.22 , $P<0.00001)$. PPNB + IRLA can lead to significantly lower biopsy pain scores when compared with PPNB alone (WMD: $-0.45,95 \%$ CI: -0.62 to $-0.28, P<0.00001$ ). PPNB + IPNB can lead to significantly lower biopsy pain scores when compared with PPNB alone (WMD: $-0.73,95 \%$ CI: -0.92 to $-0.55, P<0.00001)$. There were no severe reported general or local complications related to local anesthesia.

Conclusion: This meta-analysis indicates that a combination of PPNB and IRLA/IPNB is effective and safe in alleviating the pain during TRUS-guided prostate biopsy. Further high-quality RCTs are needed to validate this result.

Keywords: local anesthesia, biopsy, meta-analysis, pain control, prostate

\section{Introduction}

Transrectal ultrasound (TRUS)-guided biopsy is a necessary method for the exact diagnosis of prostatic carcinoma. Although it is well tolerated by many patients, the procedure can cause significant pain and discomfort. ${ }^{1}$ Severe pain can result in more patient movements or less number of biopsies, which may further lead to decreased accuracy of the diagnosis. In recent years, a consensus has been reached that sextant sampling is inadequate and sampling with $\geq 8$ cores is suggested. ${ }^{2}$ The increased number of biopsy cores converts into cumulative pain, further increasing the need for anesthesia. 
Various kinds of local anesthesia have been used before TRUS-guided prostate biopsy, but there is no agreement about the most effective one. TRUS-guided biopsy is commonly performed with intrarectal local anesthestic (IRLA), but one study has shown that $>50 \%$ of patients reported moderate-to-intolerable pain even with intrarectal lidocaine application before the procedure. ${ }^{3}$ Periprostatic nerve block (PPNB) was first adapted for TRUS-guided biopsy of the prostate by Nash et $\mathrm{al}^{3}$ in 1996. A previous study has shown its efficacy by comparing with IRLA or placebo. ${ }^{4}$ However, PPNB allows little effect in alleviating the pain associated with ultrasound probe manipulation. ${ }^{5}$ Recently, an emerging trend is to combine PPNB with IRLA or with intraprostatic nerve block (IPNB) for more comprehensive pain control, but the results remain complicated.

Therefore, it is necessary to perform a meta-analysis to evaluate the efficacy and safety of IRLA, PPNB, and the combined modalities in alleviating the pain during TRUSguided biopsy, which may be helpful to choose the optimal method of local anesthesia.

\section{Materials and methods}

\section{Search strategy}

Two independent reviewers operated a comprehensive literature review using MEDLINE, EMBASE, and the Cochrane Library from 1980 to 2016. For potentially relevant studies, the reference lists of the included studies were also checked. The following search terms were used: TRUS-guided biopsy, anesthesia, pain control, IRLA, PPNB, and IPNB.

\section{Inclusion criteria}

Studies that met the following criteria were included: 1) randomized controlled trials (RCTs) about IRLA vs no anesthesia or placebo gel; PPNB vs no injection, periprostatic placebo injection, or IRLA; combined PPNB and IRLA vs PPNB alone; and combined PPNB and IPNB vs PPNB alone before TRUS-guided biopsy; 2) pain intensity measured by visual pain scale, in which 0 point $/ \mathrm{cm}$ means no pain and 10 points/cm means maximum pain; 3) the outcome reported as mean and standard deviation; and 4) the full text of the study could be accessed.

\section{Trial selection}

If the same group of subjects was studied by multiple experiments, each study was included. If the same study

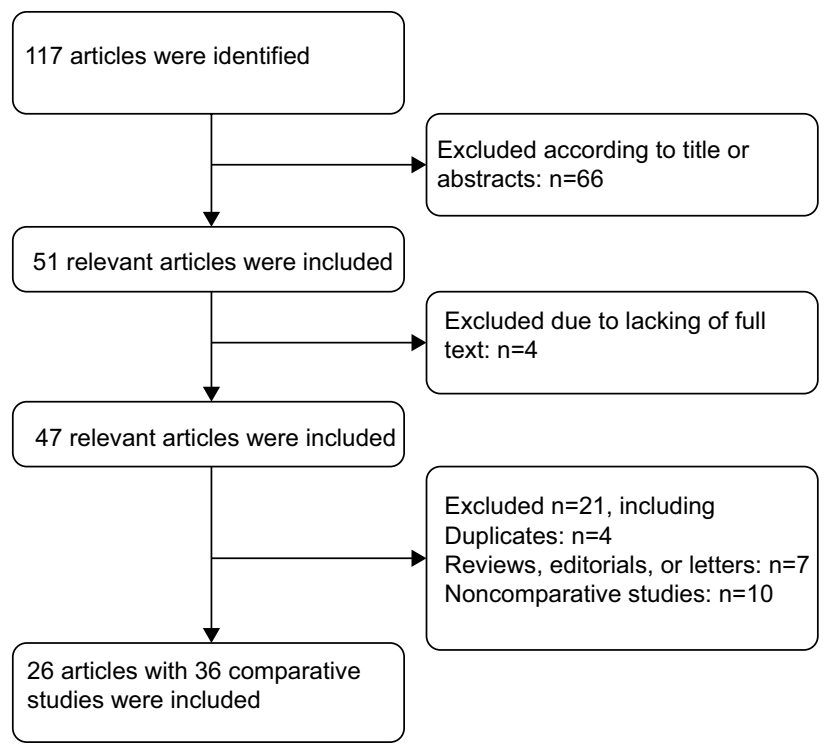

Figure I A flow diagram of the study selection process.

was published in different articles, the most frequently cited one was included. Each of the studies that were included or excluded were discussed. A flow diagram of the study selection process is presented in Figure 1.

\section{Quality assessment}

Two independent reviewers assessed the quality of the included studies according to the Preferred Reporting Items for Systematic Reviews and Meta-analyses guidelines, including assessments of random sequence generation, allocation concealment, blinding methods, and description of withdrawals and dropouts.

\section{Data extraction}

The data were extracted by two independent reviewers using a predesigned form, which included the first author's name, publication year, number of patients, interventions, and results. The main outcomes were biopsy pain score, probe manipulation pain score, and anesthetic infiltration pain score assessed by the visual pain scale. The secondary outcomes were complications related to local anesthesia.

\section{Statistical analysis}

Statistical analysis was operated by Review Manager 5.3.0. Outcomes were reported as a combination of the weighted mean difference (WMD) with $95 \% \mathrm{CI}$ and the $P$-value. $I^{2}$ heterogeneity test was used to quantify the effect of result heterogeneity. A fixed-effects model was used when $I^{2}$ was no 
$>50 \%$, otherwise a random-effects model was used. Publication bias was evaluated by using a funnel plot.

\section{Results \\ Description of the eligible studies}

There were 26 articles involving 36 studies finally eligible for this meta-analysis. ${ }^{6-31}$ Eight articles compared IRLA with no anesthesia or placebo gel; ${ }^{6-13}$ six articles compared PPNB with no anesthesia; ${ }^{7,11,14-17}$ three articles compared PPNB with periprostatic placebo injection; ${ }^{10,14,18}$ six articles compared PPNB with IRLA; $;^{7,10,11,19,21}$ nine articles compared combined PPNB and IRLA with PPNB alone; ${ }^{21-29}$ and four articles compared combined PPNB and IPNB with PPNB alone. ${ }^{15,17,30,31}$ For studies comparing PPNB with periprostatic placebo injection, an equivalent volume of normal saline was used. In all studies, biopsies were operated with an $18 \mathrm{G}$ needle, and six to 14 core biopsies were performed for the participants.

Double-blindness was not present in studies describing no anesthesia. Randomization sequencing and outcome data reporting were deemed mostly adequate. It is poorly reported about allocation concealment, withdrawals, and dropouts. The main characteristics and quality assessment of the eligible studies are presented in Table 1.

\section{Comparisons}

\section{IRLA vs no anesthesia or placebo gel}

Figure 2 shows the forest plot comparing IRLA with no anesthesia or placebo gel. Totally, there were eight studies involving 796 patients. Although IRLA can lead to pain reduction, the result was not statistically significant when compared with no anesthesia or placebo gel (WMD: -0.22 , 95\% CI: -0.45 to $0, P=0.06$ ).

In terms of probe manipulation pain, patients with IRLA had less pain scores (WMD: $-0.61,95 \%$ CI: -1.69 to 0.48 ), but there was no statistically significant difference $(P=0.27)$.

\section{PPNB vs controls}

Figure 3 shows the forest plot comparing PPNB with no anesthesia or periprostatic placebo injection. Six studies with 664 patients compared PPNB with no anesthetic. Three studies with 181 patients compared PPNB with periprostatic placebo injection. PPNB can result in significantly lower biopsy pain scores when compared with no analgesia (WMD: $-1.32,95 \%$ CI: -1.68 to $-0.95, P<0.00001$ ) or periprostatic placebo injections (WMD: $-2.62,95 \% \mathrm{CI}:-3.16$ to -2.07 , $P<0.00001)$.
In terms of probe manipulation pain, the scores had a very slight increase in patients given PPNB when compared with those given no anesthesia or periprostatic placebo injection (WMD: $0.07,95 \% \mathrm{CI}:-0.13$ to 0.26 ), but there was no statistically significant difference $(P=0.51)$.

\section{PPNB vs IRLA}

Figure 4 shows six studies involving 474 patients comparing PPNB with IRLA. PPNB can bring about significantly lower biopsy pain scores when compared with IRLA (WMD: -1.31 , $95 \%$ CI: -1.40 to $-1.22, P<0.00001)$. In terms of probe manipulation pain, the scores had a significant increase in patients given PPNB (WMD: 0.50, 95\% CI: 0.04-0.96, $P=0.03$ ).

\section{PPNB + IRLA vs PPNB alone}

Figure 5 shows nine studies involving 1,005 patients comparing PPNB + IRLA with PPNB alone. Significantly lower biopsy pain scores were resulted from PPNB + IRLA (WMD: $-0.45,95 \%$ CI: -0.62 to $-0.28, P<0.00001$ ).

In terms of probe manipulation pain, patients with PPNB + IRLA had less pain scores (WMD: $-1.64,95 \%$ CI: -3.66 to 0.39$)$, but there was no statistically significant difference $(P=0.11)$. Although PPNB + IRLA slightly alleviated the anesthetic infiltration pain (WMD: $-1.47,95 \% \mathrm{CI}:-3.00$ to 0.05$)$, the difference was not significant $(P=0.06)$.

\section{PPNB + IPNB vs PPNB alone}

Figure 6 shows four studies involving 504 patients comparing PPNB + IPNB with PPNB alone. PPNB + IPNB can bring about significantly lower biopsy pain scores when compared with PPNB alone (WMD: $-0.73,95 \%$ CI: -0.92 to -0.55 , $P<0.00001$ ).

In terms of probe manipulation pain, patients with PPNB + IPNB had less pain scores (WMD: $-0.05,95 \% \mathrm{CI}$ : -0.24 to 0.13$)$, but there was no statistically significant difference $(P=0.58)$. Although PPNB + IPNB slightly reduced the anesthetic infiltration pain (WMD: $-0.36,95 \% \mathrm{CI}:-0.98$ to 0.26$)$, the difference was not significant $(P=0.25)$.

\section{Safety}

There were only three studies that did not report the complication rates. ${ }^{11,13,29}$ For those reported, the only adverse effect related to local anesthesia was headache by using glyceryl trinitrate ointment intrarectally. ${ }^{27}$ Moreover, there was almost no significant difference of postoperative complications between different kinds of local anesthesia during shortterm follow-up, such as fever, hematuria, hematospermia, rectal bleeding, dysuria, and acute urinary retention, except 
Table I Main characteristics and quality assessment of the eligible studies

\begin{tabular}{|c|c|c|c|c|c|}
\hline Study & Number of patients & Studies & $\begin{array}{l}\text { Anesthetics (I. IRLA, } \\
\text { 2. PPNB, and 3. IPNB) }\end{array}$ & Biopsy cores & $\begin{array}{l}\text { Quality } \\
\text { assessment }\end{array}$ \\
\hline Kandirali et al ${ }^{6}$ & 80 & IRLA vs no anesthesia & $\begin{array}{l}\text { I. Lidocaine-prilocaine cream } \\
(5 \mathrm{~mL})\end{array}$ & 12 & B \\
\hline Gurbuz et $\mathrm{al}^{7}$ & 100 & $\begin{array}{l}\text { IRLA vs no anesthesia } \\
\text { PPNB vs no anesthesia } \\
\text { PPNB vs IRLA }\end{array}$ & $\begin{array}{l}\text { I. Lidocaine-prilocaine cream } \\
(5 \mathrm{~mL}) \\
\text { 2. I\% lidocaine }(10 \mathrm{~mL})\end{array}$ & 10 & A \\
\hline Adamakis et $\mathrm{a}^{8}$ & 198 & IRLA vs no anesthesia & $\begin{array}{l}\text { I. } 5 \% \text { lidocaine-prilocaine cream } \\
(10 \mathrm{~mL})\end{array}$ & 10 & B \\
\hline Leung et $\mathrm{al}^{9}$ & 338 & IRLA vs no anesthesia & I. $2 \%$ lidocaine gel $(10 \mathrm{~mL})$ & $N$ & B \\
\hline Song et $\mathrm{al}^{10}$ & 90 & $\begin{array}{l}\text { IRLA vs no anesthesia } \\
\text { PPNB vs placebo } \\
\text { PPNB vs IRLA }\end{array}$ & $\begin{array}{l}\text { I. } 2 \% \text { lidocaine gel }(20 \mathrm{~mL}) \\
\text { 2. } 2 \% \text { lidocaine }(5 \mathrm{~mL})\end{array}$ & 10 & B \\
\hline Stirling et al" & 150 & $\begin{array}{l}\text { IRLA vs no anesthesia } \\
\text { PPNB vs no anesthesia } \\
\text { PPNB vs IRLA }\end{array}$ & $\begin{array}{l}\text { I. } 1 \% \text { lidocaine gel }(10 \mathrm{~mL}) \\
\text { 2. } 1 \% \text { lidocaine }(10 \mathrm{~mL})\end{array}$ & 8 & A \\
\hline Trucchi et al ${ }^{12}$ & 60 & IRLA vs no anesthesia & I. $2 \%$ lidocaine gel $(10 \mathrm{~mL})$ & 10 & B \\
\hline Yurdakul et al ${ }^{13}$ & 100 & IRLA vs no anesthesia & I. $2 \%$ lidocaine gel $(10 \mathrm{~mL})$ & 10 & B \\
\hline Inal et $\mathrm{al}^{14}$ & 98 & $\begin{array}{l}\text { PPNB vs no anesthesia } \\
\text { PPNB vs placebo }\end{array}$ & 2. $1 \%$ lidocaine $(3 \mathrm{~mL})$ & $6-12$ & A \\
\hline Bingqian et $\mathrm{al}^{15}$ & 300 & $\begin{array}{l}\text { PPNB vs no anesthesia } \\
\text { PPNB + IPNB vs PPNB }\end{array}$ & $\begin{array}{l}\text { 2. } 2 \% \text { lidocaine }(5 \mathrm{~mL}) \\
\text { 3. } 2 \% \text { lidocaine }(5 \mathrm{~mL})\end{array}$ & 14 & A \\
\hline Manikandan et al ${ }^{16}$ & 235 & PPNB vs no anesthesia & 2. I\% lidocaine $(10 \mathrm{~mL})$ & $\mathrm{N}$ & B \\
\hline Singh et a $\left.\right|^{17}$ & 142 & $\begin{array}{l}\text { PPNB vs no anesthesia } \\
\text { PPNB + IPNB vs PPNB }\end{array}$ & $\begin{array}{l}\text { 2. } 1 \% \text { lignocaine }(10 \mathrm{~mL}) \\
\text { 3. } 1 \% \text { lignocaine }(5 \mathrm{~mL})\end{array}$ & 12 & A \\
\hline Seçkiner et al ${ }^{18}$ & 112 & PPNB vs placebo & 2. $2 \%$ lidocaine $(2.5 \mathrm{~mL})$ & $N$ & A \\
\hline Aktoz et al ${ }^{19}$ & 90 & PPNB vs IRLA & $\begin{array}{l}\text { I. Diclofenac sodium suppository } \\
(50 \mathrm{mg}) \\
\text { 2. } 0.75 \% \text { levobupivacaine }(3.3 \mathrm{~mL})\end{array}$ & 10 & A \\
\hline Alavi et a $\mathrm{a}^{20}$ & 150 & PPNB vs IRLA & $\begin{array}{l}\text { I. } 2 \% \text { lidocaine gel }(10 \mathrm{~mL}) \\
\text { 2. } 1 \% \text { lidocaine }(10 \mathrm{~mL})\end{array}$ & $6-14$ & A \\
\hline Inal et $\mathrm{a}^{21}$ & 159 & $\begin{array}{l}\text { PPNB vs IRLA } \\
\text { PPNB + IRLA vs PPNB }\end{array}$ & $\begin{array}{l}\text { I. } 2 \% \text { lidocaine gel }(10 \mathrm{~mL}) \\
\text { 2. } 1 \% \text { lidocaine }(6 \mathrm{~mL})\end{array}$ & $6-12$ & $A$ \\
\hline Giannarini et a $\left.\right|^{22}$ & 280 & PPNB + IRLA vs PPNB & $\begin{array}{l}\text { I. Lidocaine-prilocaine cream } \\
(5 \mathrm{~mL}) \\
\text { 2. } 1 \% \text { lidocaine }(10 \mathrm{~mL})\end{array}$ & 10 & $A$ \\
\hline Noh et $\mathrm{al}^{23}$ & 74 & PPNB + IRLA vs PPNB & $\begin{array}{l}\text { I. Lidocaine-prilocaine cream } \\
(5 \mathrm{~mL}) \\
\text { 2. } 1 \% \text { lidocaine }(10 \mathrm{~mL})\end{array}$ & 12 & A \\
\hline Obek et a $\left.\right|^{24}$ & 75 & PPNB + IRLA vs PPNB & $\begin{array}{l}\text { I. } 2 \% \text { lidocaine gel }(10 \mathrm{~mL}) \\
\text { 2. } 2 \% \text { lidocaine }(5 \mathrm{~mL})\end{array}$ & 12 & B \\
\hline Ooi et $\mathrm{al}^{25}$ & 96 & PPNB + IRLA vs PPNB & $\begin{array}{l}\text { I. Diclofenac suppository }(100 \mathrm{mg}) \\
\text { 2. I\% lidocaine }(10 \mathrm{~mL})\end{array}$ & 14 & A \\
\hline Raber et $\mathrm{a}^{26}$ & 300 & PPNB + IRLA vs PPNB & $\begin{array}{l}\text { I. Lidocaine-prilocaine cream } \\
(5 \mathrm{~mL}) \\
\text { 2. } 2 \% \text { lidocaine }(10 \mathrm{~mL})\end{array}$ & 14 & $A$ \\
\hline Skriapas et $\mathrm{al}^{27}$ & 223 & PPNB + IRLA vs PPNB & $\begin{array}{l}\text { I. } 0.4 \% \text { glyceryl trinitrate ointment } \\
(\mathrm{I} \mathrm{mg}) \\
\text { 2. } 2 \% \text { lidocaine }(5 \mathrm{~mL})\end{array}$ & 12 & $A$ \\
\hline Szlauer et $\mathrm{a}^{28}$ & 100 & PPNB + IRLA vs PPNB & $\begin{array}{l}\text { I. } 2 \% \text { lidocaine gel }(10 \mathrm{~mL}) \\
\text { 2. } 2 \% \text { lidocaine }(5 \mathrm{~mL})\end{array}$ & $\mathrm{N}$ & $A$ \\
\hline Yun et $\mathrm{al}^{29}$ & 250 & PPNB + IRLA vs PPNB & $\begin{array}{l}\text { I. } 2 \% \text { lidocaine gel }(10 \mathrm{~mL}) \\
\text { 2. } 1 \% \text { lidocaine }(8 \mathrm{~mL})\end{array}$ & 12 & A \\
\hline Kumar et $\mathrm{al}^{30}$ & 150 & PPNB + IPNB vs PPNB & $\begin{array}{l}\text { 2. } 1 \% \text { lidocaine }(10 \mathrm{~mL}) \\
\text { 3. } 1 \% \text { lidocaine }(5 \mathrm{~mL})\end{array}$ & 12 & A \\
\hline Lee et $\mathrm{al}^{31}$ & 152 & PPNB + IPNB vs PPNB & $\begin{array}{l}\text { 2. } 1 \% \text { lidocaine }(2 \mathrm{~mL}) \\
\text { 3. } 1 \% \text { lidocaine }(2 \mathrm{~mL})\end{array}$ & 12 & $A$ \\
\hline
\end{tabular}

Note: ${ }^{a} \mathrm{~A}$ : all quality criteria met (adequate), low risk of bias; B: one or more of the quality criteria only partly met (unclear), moderate risk of bias; N, no relevant information present.

Abbreviations: IPNB, intraprostatic nerve block; IRLA, intrarectal local anesthestic; PPNB, periprostatic nerve block. 


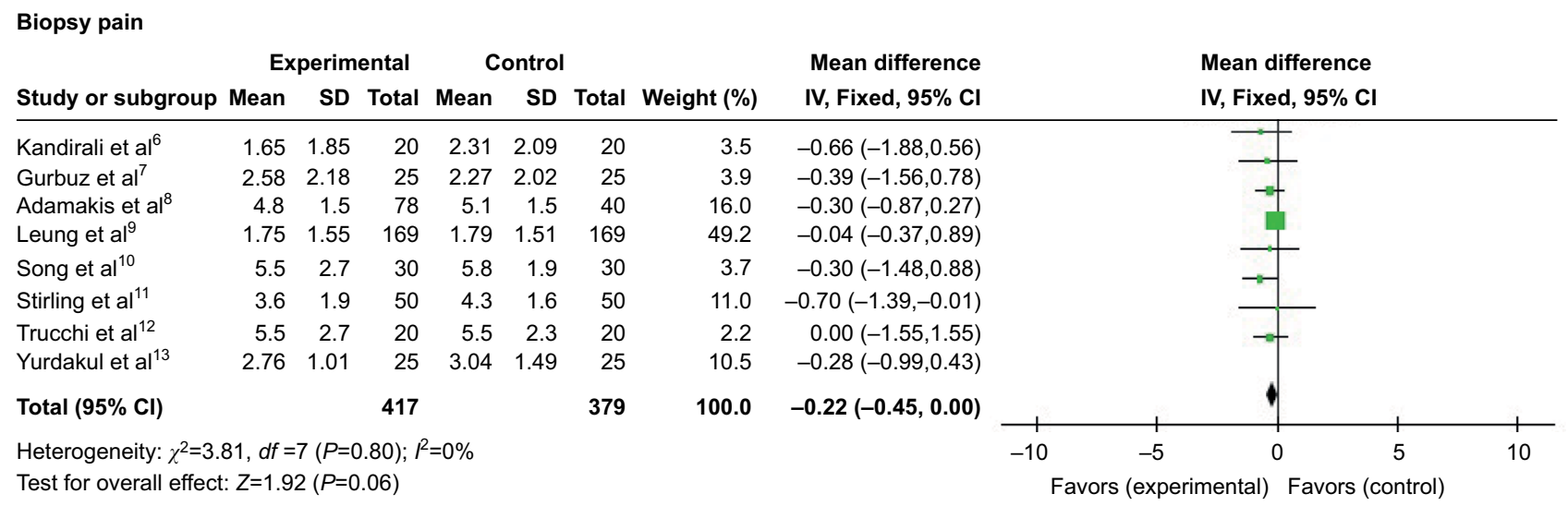

Probe manipulation pain

\begin{tabular}{lrrrrrrrr} 
& \multicolumn{3}{c}{ Experimental } & \multicolumn{3}{c}{ Control } & Mean difference \\
Study or subgroup Mean & SD & Total & Mean & SD & Total Weight (\%) & IV, Random 95\% CI \\
\hline Kandirali et al $^{6}$ & 5.08 & 2.1 & 20 & 5.21 & 2.3 & 20 & 27.1 & $-0.13(-1.49,1.23)$ \\
Gurbuz et al $^{7}$ & 2.5 & 1.77 & 25 & 2.48 & 1.73 & 25 & 34.3 & $-0.02(-0.95,0.99)$ \\
Stirling et al ${ }^{11}$ & 2.2 & 1.7 & 50 & 3.7 & 2.1 & 50 & 38.6 & $-1.50(-2.25,-0.75)$ \\
Total (95\% Cl) & & & $\mathbf{9 5}$ & & & $\mathbf{9 5}$ & $\mathbf{1 0 0 . 0}$ & $\mathbf{- 0 . 6 1 ( - 1 . 6 9 , 0 . 4 8 )}$
\end{tabular}

Heterogeneity: $\tau^{2}=0.65 ; \chi^{2}=7.03, d f=2(P=0.03) ; l^{2}=72 \%$

Test for overall effect: $Z=1.10(P=0.27)$

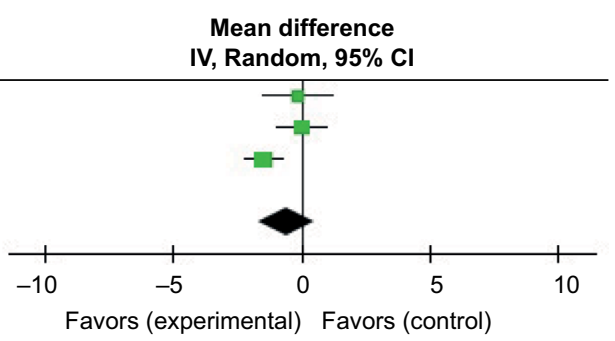

Figure 2 Forest plot comparing IRLA with control.

Abbreviation: $\mathrm{Cl}$, confidence interval; IRLA, intrarectal local anesthestic; SD, standard deviation; IV, means inverse variance.

one study showing that fever rate was obviously higher in group PPNB + IRLA when compared with group PPNB, but rehospitalization was not necessary. ${ }^{24}$

\section{Discussion}

Nowadays, IRLA and PPNB are the most common methods for pain control during TRUS-guided prostate biopsy. There are two factors mainly associated with the pain during prostate biopsy: discomfort originating from the insertion and movement of TRUS probe in the rectum and the insertion of needles into the prostate gland. However, neither of the methods alone can offer satisfactory pain control. It is necessary to further explore the optimal method of local anesthesia for TRUS-guided prostate biopsy.

\section{Intrarectal local anesthestic}

Because of the excellent drug absorptive qualities of the rectal wall and the close proximity of inferolateral nerves of prostate to the rectal wall, IRLA would anesthetize the nerves. ${ }^{10}$ Stirling et $\mathrm{al}^{11}$ have found out that patients with IRLA had significantly less biopsy pain scores than those without anesthesia, but the authors found that IRLA did not provide better pain control than no anesthesia or placebo gel. In addition, Stirling et al ${ }^{11}$ reported that patients with IRLA had less probe insertion scores than those with no anesthesia, which was different from the results of this study. These differences were probably due to the usage of different anesthetic agents or the thickness of the ultrasound probe. Overall, it is not enough to make sufficient pain control throughout the process using IRLA alone.

\section{Periprostatic nerve block}

It was found that PPNB can significantly reduce the biopsy pain score during TRUS-guided prostate biopsy when compared with no anesthesia, periprostatic placebo injection, or IRLA. The results seemed consistent with most of the studies. ${ }^{7,10,11,14}$ In addition, Tiong et $\mathrm{al}^{32}$ reported that it can be effective over a wide range of different volumes, concentrations, and types of local anesthesia. Probe manipulation pain score had a slight increase in patients given PPNB when compared with those given no anesthesia or periprostatic placebo injection. Nevertheless, it had a significant increase in patients given PPNB when compared with those given IRLA. The previous studies have reported that after PPNB 


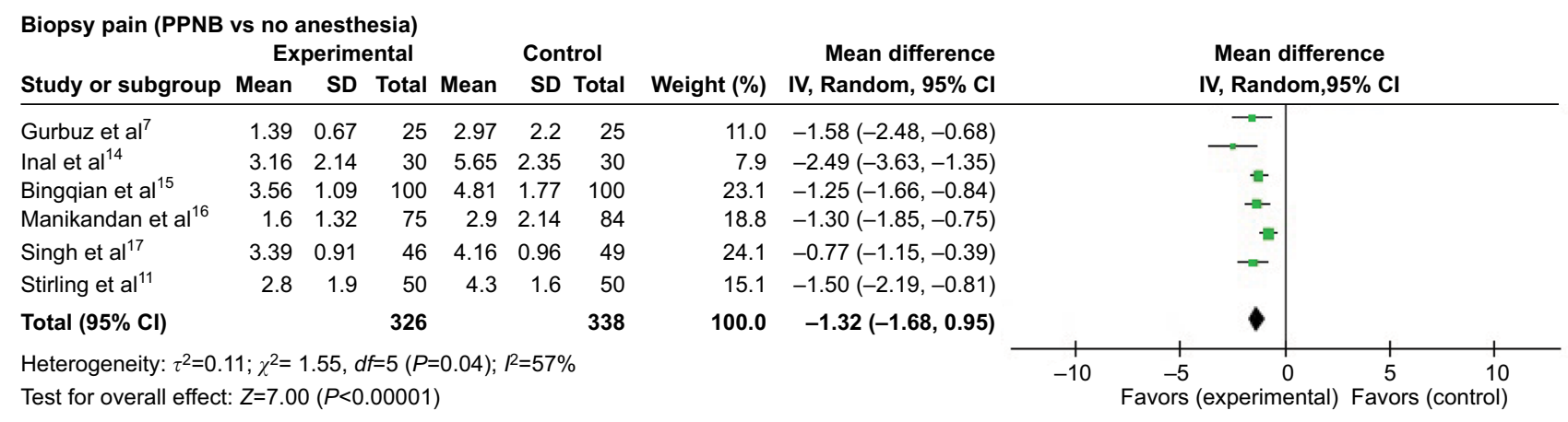

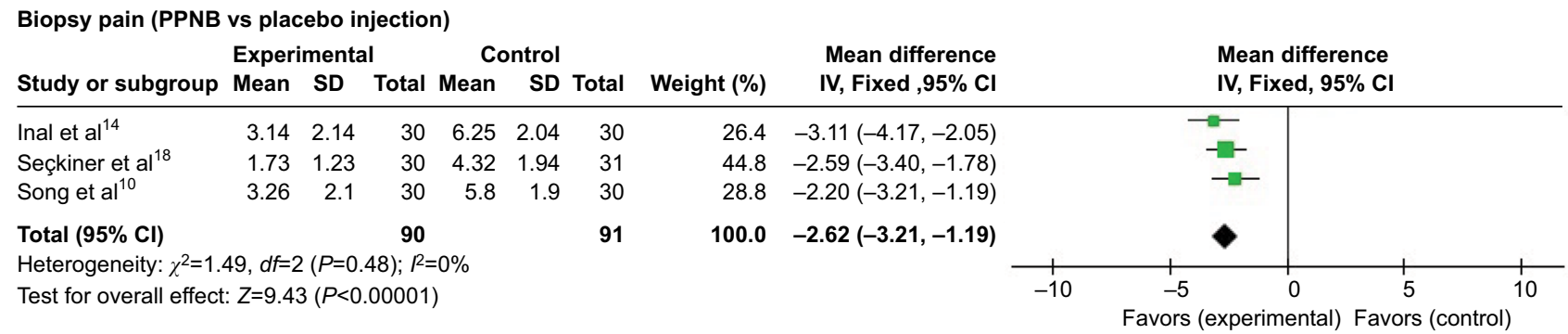

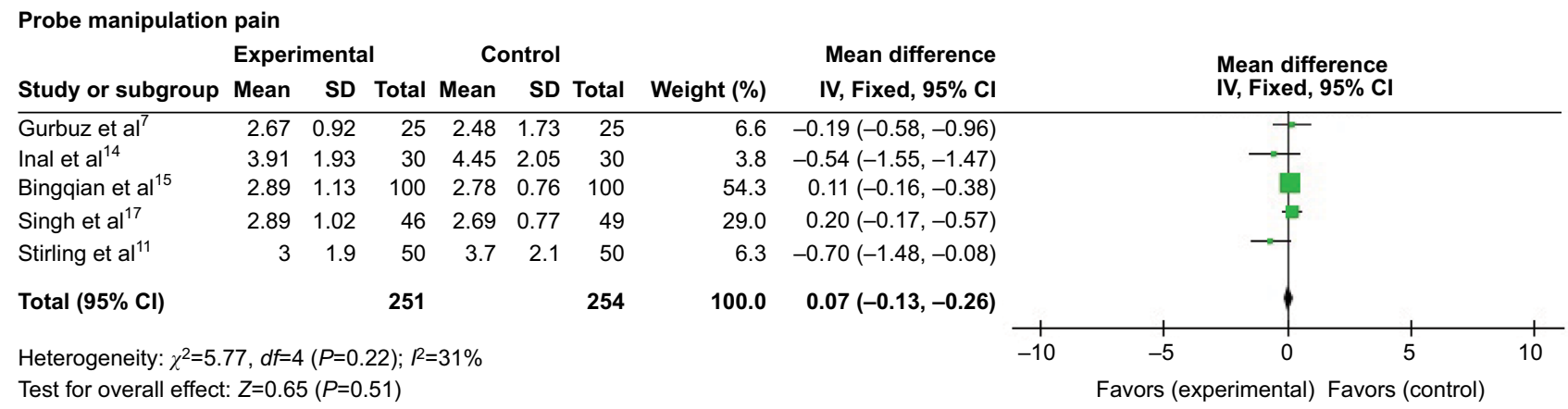

Figure 3 Forest plot comparing PPNB with different controls.

Abbreviation: $\mathrm{Cl}$, confidence interval; PPNB, periprostatic nerve block; SD, standard deviation.

anesthesia, the introduction of the probe was significantly more painful than the biopsy itself. ${ }^{24,27}$ That the reason may be that PPNB around the neurovascular bundles of prostate can provide sufficient pain control for insertion of needles into the prostate gland but cannot lead to anorectal muscle relaxation related to probe manipulation pain.

In terms of safety, Obek et $\mathrm{al}^{33}$ reported that PPNB increases infection rates and bacteriuria after the biopsy, but there were no significant differences of short-term postoperative complications between PPNB and no anesthesia, periprostatic placebo injection, or IRLA in studies included in this meta-analysis.

\section{PPNB + IRLA}

Recently, an emerging trend is to combine PPNB with IRLA for more comprehensive pain control. Obek et $\mathrm{al}^{24}$ reported that this combined modality offered better anesthetic effect than PPNB alone. The results confirmed his published report, which might be explained by the former finding that discomfort of probe manipulation could increase the stress and anxiety of patients and adds to their perception of the following biopsy pain, that is, the positive correlation of anorectal compliance and pain tolerance. ${ }^{5}$ In this meta-analysis, both probe manipulation pain score and anesthetic infiltration pain score were less in patients given PPNB + IRLA, but the difference was not statistically significant.

\section{PPNB + IPNB}

Mutaguchi et $\mathrm{al}^{34}$ proposed a new local anesthesia technique to anesthetize the prostate that required blocking all sensory nerves from the posterior and anterior sides in 2005. The 


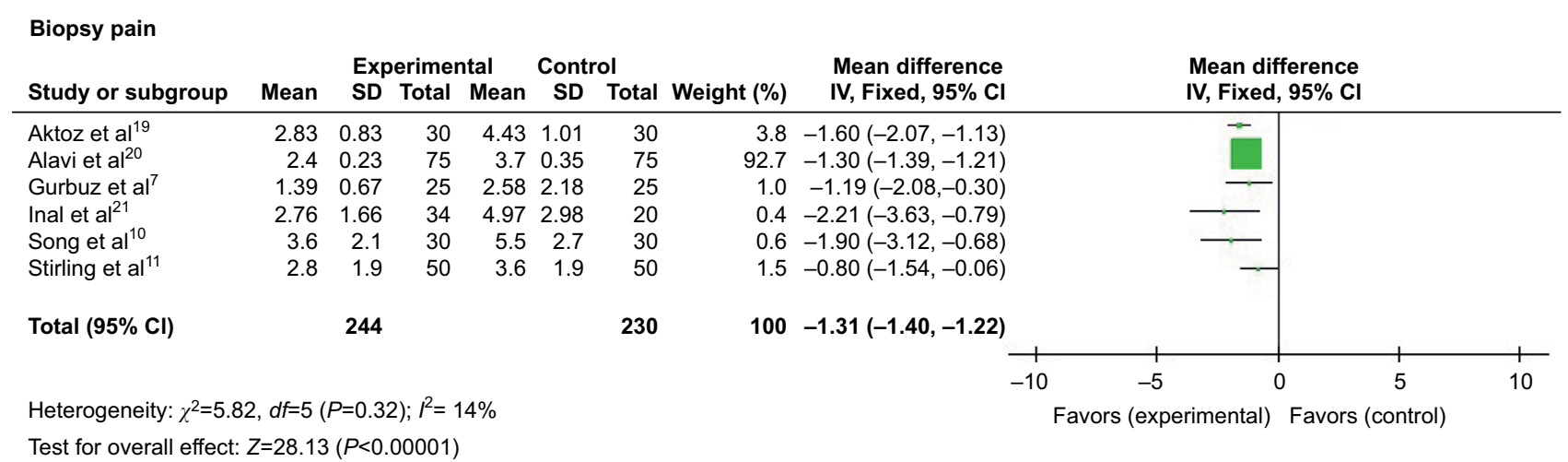

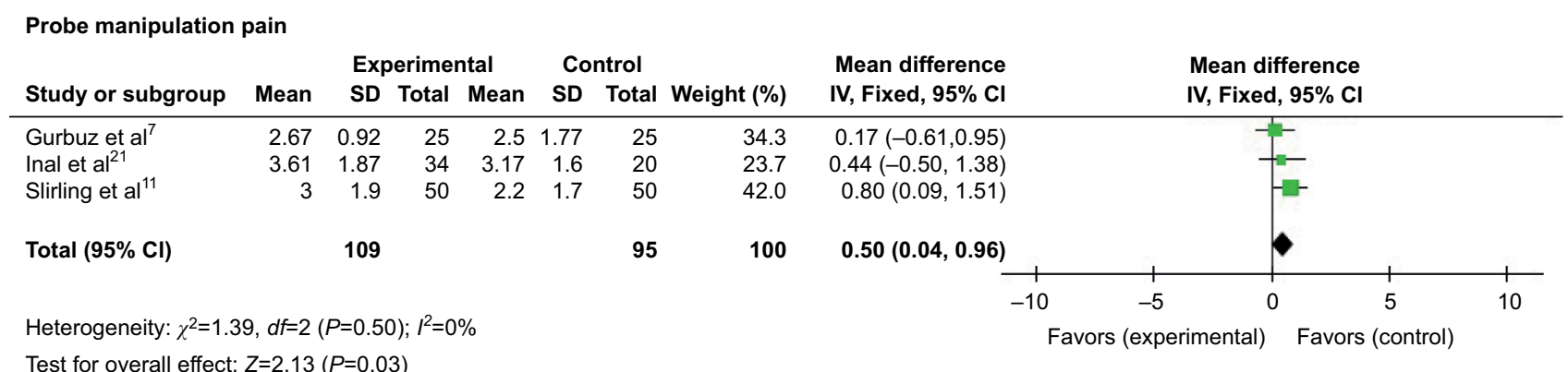

Figure 4 Forest plot comparing PPNB with IRLA.

Abbreviations: $\mathrm{Cl}$, confidence interval; IRLA, intrarectal local anesthestic; PPNB, periprostatic nerve block; SD, standard deviation.

main contribution of combined anesthesia is more effective blockage of sensory fibers. The superiority of combined PPNB and IPNB to control pain during biopsy was also clearly noted. Although this combination slightly reduced the anesthetic infiltration pain and probe manipulation pain, the difference was not statistically significant. Moreover, no evidence was found to support more severe complications related to PPNB + IPNB.

\section{Selection of optimal method of local anesthesia}

Pain is difficult to quantify due to its complex perceptual nature. Not all patients require the same form of pain control, and some patients might not even require anesthesia at all, but some researchers have shown that the pain level does increase significantly with increasing number of biopsies. ${ }^{35,36}$ It was found that the combined modalities produced superior pain control without increased complications. Although there was no study comparing PPNB + IRLA with PPNB + IPNB, PPNB + IPNB demanded more complicated technology because direct intraprostatic injection had to be done under ultrasound guidance. Considering the prolonged operating time and increased costs owing to the combined modalities, it is important to identify suitable patients that would benefit most from them. Studies within this meta-analysis show that younger patients with greater prostate volume and with rectal complications are more prone to pain and benefit more from the combined modalities. ${ }^{15,22,26}$

The limitations of this meta-analysis mainly generated from the heterogeneity of study designs, including racial and age differences, numbers of core biopsies, caliber and shape of the ultrasound probes, and anesthetic type and dosage; using a random-effects model can reduce this heterogeneity but still cannot eliminate it. Subgroup analysis was not carried out due to an insufficient amount of data. Furthermore, more RCTs about PPNB vs IPNB are expected to evaluate the better one.

\section{Conclusion}

This meta-analysis indicates that a combination of PPNB and IRLA/IPNB is effective and safe in alleviating the pain during TRUS-guided prostate biopsy. Further high-quality RCTs are needed to validate this result.

\section{Acknowledgment}

Pu Yan and Xiao-yan Wang are the co-first authors. 


\section{Biopsy pain}

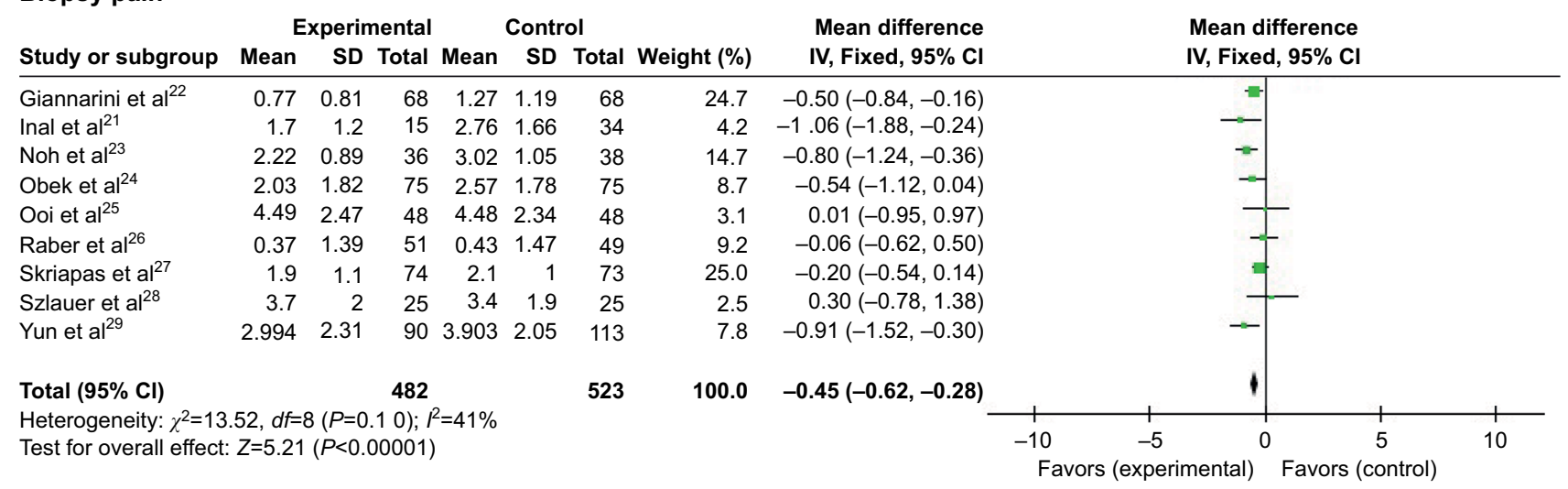

Probe manipulation pain

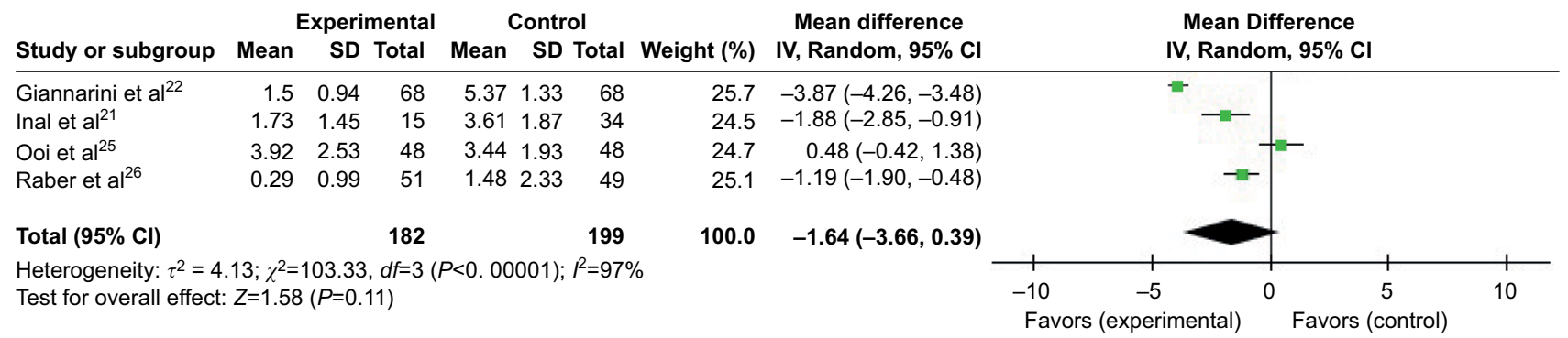

Anesthetic infiltration pain

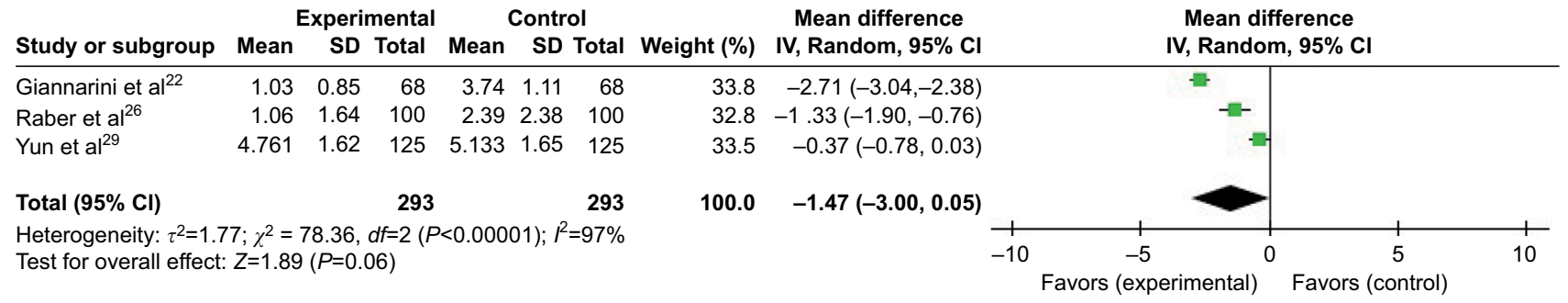

Figure 5 Forest plot comparing PPNB + IRLA with PPNB.

Abbreviations: $\mathrm{Cl}$, confidence interval; IRLA, intrarectal local anesthestic; PPNB, periprostatic nerve block; SD, standard deviation. 
Biopsy pain

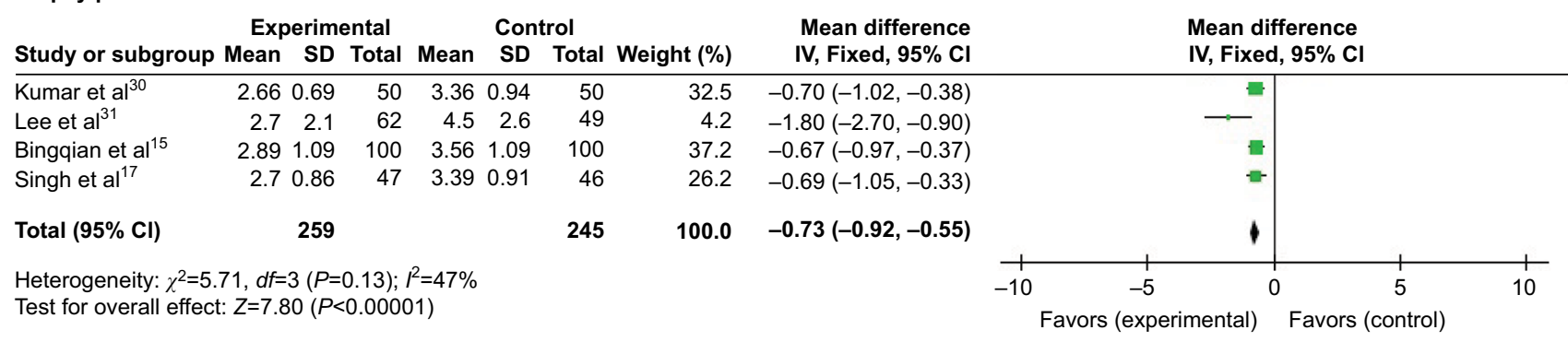

Probe manipulation pain

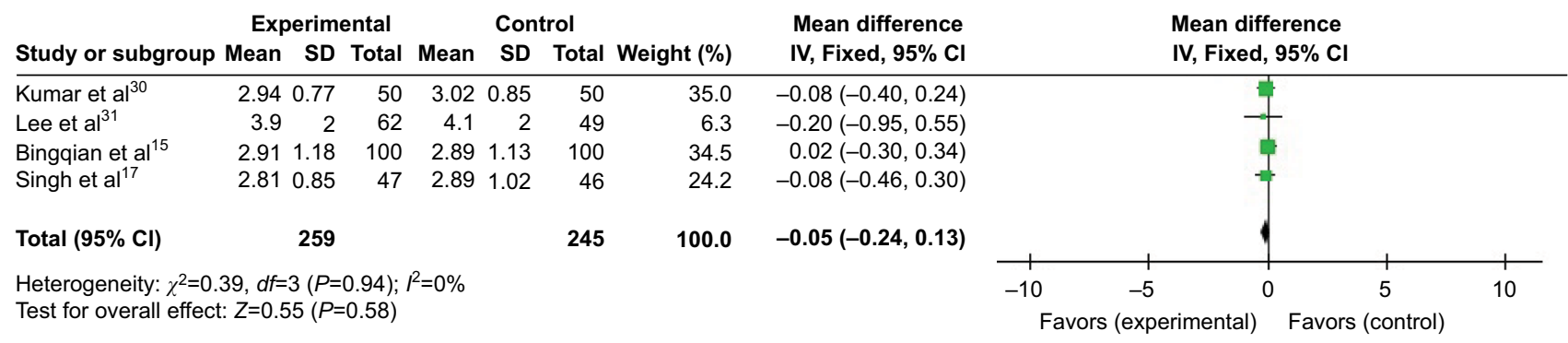

Anesthetic infiltration pain

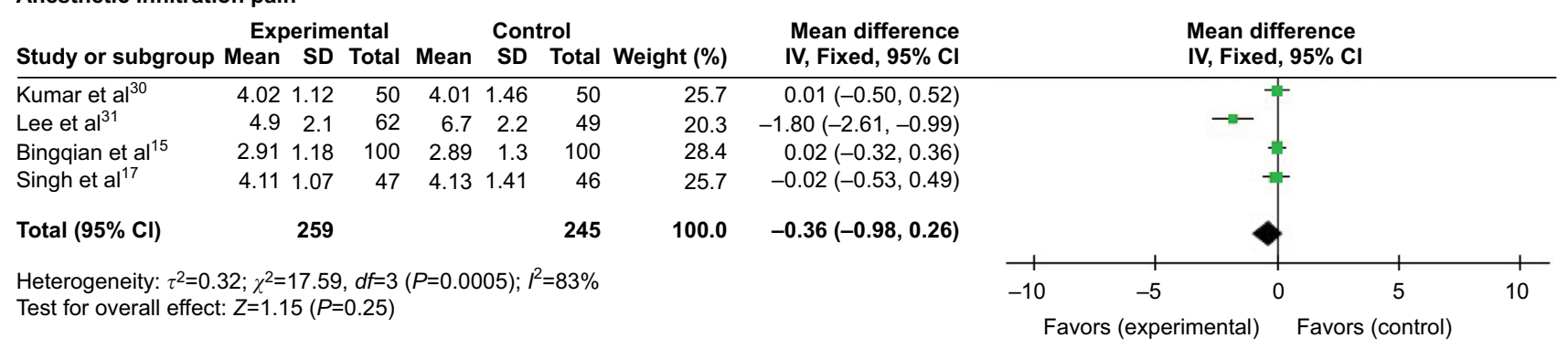

Figure 6 Forest plot comparing PPNB + IPNB with PPNB.

Abbreviations: $\mathrm{Cl}$, confidence interval; IPNB, intraprostatic nerve block; PPNB, periprostatic nerve block; SD, standard deviation.

\section{Disclosure}

The authors report no conflicts of interest in this work.

\section{References}

1. Autorino R, De Sio M, Di Lorenzo G, et al. How to decrease pain during transrectal ultrasound guided prostate biopsy: a look at the literature. J Urol. 2005;174(6):2091-2097.

2. Ochiai A, Babaian RJ. Update on prostate biopsy technique. Curr Opin Urol. 2004;14:157-162.

3. Nash PA, Bruce JE, Indudhara R, Shinohara K. Transrectal ultrasound guided prostatic nerve blockade eases systematic needle biopsy of the prostate. J Urol. 1996;155(2):607-609.

4. Hergan L, Kashefi C, Parsons JK. Local anesthetic reduces pain associated with transrectal ultrasound-guided prostate biopsy: a meta-analysis. Urology. 2007;69(3):520-525.

5. McCabe JE, Hanchanale VS, Philip J, Javle PM. A randomized controlled trial of topical glyceryl trinitrate before transrectal ultrasonography-guided biopsy of the prostate. BJU Int. 2007;100:536-538; discussion 538-539.

6. Kandirali E, Ulukaradag E, Uysal B, Serin E, Semercioz A, Metin A. Is only perianal anesthesia with lidocaine-prilocaine cream sufficient to decrease the pain during transrectal ultrasound-guided prostate biopsy? A prospective randomized study. Urol Int. 2009;82(3):262-265.
7. Gurbuz C, Canat L, Bayram G, Gokhan A, Samet G, Caskurlu T. Visual pain score during transrectal ultrasound-guided prostate biopsy using no anaesthesia or three different types of local anaesthetic application. Scand J Urol Nephrol. 2010;44(4):212-216.

8. Adamakis I, Mitropoulos D, Haritopoulos K, Alamanis C, Stravodimos K, Giannopoulos A. Pain during transrectal ultrasonography guided prostate biopsy: a randomized prospective trial comparing periprostatic infiltration with lidocaine with the intrarectal instillation of lidocaineprilocaine cream. World J Urol. 2004;22(4):281-284.

9. Leung SY, Wong BB, Cheung MC, Ho KL, Lee FC, Tam PC. Intrarectal administration of lidocaine gel versus plain lubricant gel for pain control during transrectal ultrasound-guided extensive 10-core prostate biopsy in Hong Kong Chinese population: prospective double-blind randomised controlled trial. Hong Kong Med J. 2006;12(2):103-107.

10. Song SH, Kim JK, Song K, Ahn H, Kim CS. Effectiveness of local anaesthesia techniques in patients undergoing transrectal ultrasoundguided prostate biopsy: a prospective randomized study. Int J Urol. 2006;13(6):707-710.

11. Stirling BN, Shockley KF, Carothers GG, Maatman TJ. Comparison of local anesthesia techniques during transrectal ultrasound-guided biopsies. Urology. 2002;60(1):89-92.

12. Trucchi A, De Nunzio C, Mariani S, Palleschi G, Miano L, Tubaro A. Local anesthesia reduces pain associated with transrectal prostatic biopsy. A prospective randomized study. Urol Int. 2005;74(3):209-213. 
13. Yurdakul T, Taspinar B, Kilic O, Kilinc M, Serarslan A. Topical and long-acting local anesthetic for prostate biopsy: a prospective randomized placebo-controlled study. Urol Int. 2009;83(2):151-154.

14. Inal G, Yazici S, Adsan O, Ozturk B, Kosan M, Cetinkaya M. Effect of periprostatic nerve blockade before transrectal ultrasound-guided prostate biopsy on patient comfort: a randomized placebo controlled study. Int J Urol. 2004;11(3):148-151.

15. Bingqian L, Peihuan L, Yudong W, Jinxing W, Zhiyong W. Intraprostatic local anesthesia with periprostatic nerve block for transrectal ultrasound guided prostate biopsy. J Urol. 2009;182(2):479-483.

16. Manikandan R, Srirangam SJ, Brown SC, O’Reilly PH, Collins GN. Nitrous oxide vs periprostatic nerve block with $1 \%$ lidocaine during transrectal ultrasound guided biopsy of the prostate: a prospective, randomized, controlled trial. J Urol. 2003;170(5):1881-1883.

17. Singh SK, Kumar A, Griwan MS, Sen J. Comparative evaluation of periprostatic nerve block with and without intraprostatic nerve block in transrectal ultrasound-guided prostatic needle biopsy. Korean J Urol. 2012;53(8):547-551.

18. Seçkiner I, Sen H, Erturhan S, Yağcı F. A prospective, randomized controlled study comparing lidocaine and tramadol in periprostatic nerve blockage for transrectal ultrasound-guided prostate biopsy. Urology. 2011;78(2):257-260.

19. Aktoz T, Kaplan M, Turan U, Memis D, Atakan IH, Inci O. 'Multimodal' approach to management of prostate biopsy pain and effects on sexual function: efficacy of levobupivacaine adjuvant to diclofenac sodium - a prospective randomized trial. Andrologia. 2010;42(1):35-40.

20. Alavi AS, Soloway MS, Vaidya A, Lynne CM, Gheiler EL. Local anesthesia for ultrasound guided prostate biopsy: a prospective randomized trial comparing 2 methods. J Urol. 2001;166(4):1343-1345.

21. Inal G, Adsan O, Ugurlu O, Kaygisiz O, Kosan M, Cetinkaya M. Comparison of four different anesthesia methods for relief of all pain during transrectal ultrasound-guided prostate biopsy. Int Urol Nephrol. 2008;40(2):335-339.

22. Giannarini G, Autorino R, Valent F, et al. Combination of perianalintrarectal lidocaine-prilocaine cream and periprostatic nerve block for pain control during transrectal ultrasound guided prostate biopsy: a randomized, controlled trial. J Urol. 2009;181(2):585-591.

23. Noh DH, Cho MC, Park HK, Lee HW, Lee KS. The effects of combination perianal-intrarectal lidocaine-prilocaine cream and periprostatic nerve block for pain control during transrectal ultrasound guided biopsy of the prostate: a randomized, controlled trial. Korean JUrol. 2010;51(7):463-466.

24. Obek C, Ozkan B, Tunc B, Can G, Yalcin V, Solok V. Comparison of 3 different methods of anesthesia before transrectal prostate biopsy: a prospective randomized trial. J Urol. 2004;172(2):502-505.
25. Ooi WL, Hawks C, Tan AH, Hayne D. A randomised controlled trial comparing use of lignocaine periprostatic nerve block alone and combined with diclofenac suppository for patients undergoing transrectal ultrasound (TRUS)-guided prostate biopsy. BJU Int. 2014;114(suppl 1): 45-49.

26. Raber M, Scattoni V, Roscigno M, et al. Topical prilocaine-lidocaine cream combined with peripheral nerve block improves pain control in prostatic biopsy: results from a prospective randomized trial. Eur Urol. 2008; 53(5):967-973.

27. Skriapas K, Konstantinidis C, Samarinas M, Xanthis S, Gekas A. Comparison between lidocaine and glyceryl trinitrate ointment for perianal-intrarectal local anesthesia before transrectal ultrasonographyguided prostate biopsy: a placebo-controlled trial. Urology. 2011;77(4): 905-908.

28. Szlauer R, Paras L, Fink KG. Addition of lidocaine suppositories to periprostatic nerve block enhances pain control in prostate biopsies: a placebo-controlled randomized trial. Urol Int. 2010;84(4):413-417.

29. Yun TJ, Lee HJ, Kim SH, Lee SE, Cho JY, Seong CK. Does the intrarectal instillation of lidocaine gel before periprostatic neurovascular bundle block during transrectal ultrasound guided prostate biopsies improve analgesic efficacy? A prospective, randomized trial. J Urol. 2007;178(1): 103-106.

30. Kumar A, Griwan MS, Singh SK, Sen J, Pawar DS. Is periprostatic nerve block a gold standard in case of transrectal ultrasound-guided prostate biopsy? Urol Ann. 2013;5(3):152-156.

31. Lee HY, Lee HJ, Byun SS, Lee SE, Hong SK, Kim SH. Effect of intraprostatic local anesthesia during transrectal ultrasound guided prostate biopsy: comparison of 3 methods in a randomized, double-blind, placebo controlled trial. J Urol. 2007;178(2):469-472.

32. Tiong HY, Liew LC, Samuel M, Consigliere D, Esuvaranathan K. A meta-analysis of local anesthesia for transrectal ultrasound-guided biopsy of the prostate. Prostate Cancer Prostatic Dis. 2007;10(2):127-136.

33. Obek C, Onal B, Ozkan B, Onder AU, Yalcin V, Solok V. Is periprostatic local anesthesia for transrectal ultrasound guided prostate biopsy associated with increased infectious or hemorrhagic complications? A prospective randomized trial. $J$ Urol. 2002;168(2):558-561.

34. Mutaguchi K, Shinohara K, Matsubara A, Yasumoto H, Mita K, Usui T. Local anesthesia during 10 core biopsy of the prostate: comparison of 2 methods. J Urol. 2005;173(3):742.

35. Kaver I, Mabjeesh NJ, Matzkin H. Randomized prospective study of periprostatic local anesthesia during transrectal ultrasound-guided prostate biopsy. Urology. 2002;59(3):405-408.

36. Schostak M, Christoph F, Muller M, et al. Optimizing local anesthesia during 10 core biopsy of the prostate. Urology. 2002;60(2):253.
Journal of Pain Research

\section{Publish your work in this journal}

The Journal of Pain Research is an international, peer reviewed, open access, online journal that welcomes laboratory and clinical findings in the fields of pain research and the prevention and management of pain. Original research, reviews, symposium reports, hypothesis formation and commentaries are all considered for publication.

\section{Dovepress}

The manuscript management system is completely online and includes a very quick and fair peer-review system, which is all easy to use. Visit http://www.dovepress.com/testimonials.php to read real quotes from published authors. 